\title{
Evaluation of a Spanish Health Topics Course for Undergraduate Pre-health Latino Students
}

\author{
Pilar Ortega ${ }^{1}$, Yoon Soo Park ${ }^{1}$, Alicia J. Rodriguez ${ }^{2}$, Jorge A. Girotti ${ }^{1}$ \\ 1. Medical Education, University of Illinois, Chicago College of Medicine, Chicago, USA 2. Miscellaneous, Arturo \\ Velásquez Institute of Richard J. Daley College, Chicago, USA
}

Corresponding author: Pilar Ortega, portega1@uic.edu

\begin{abstract}
Introduction: Language concordance between doctors and patients and increased matriculation of underrepresented minorities in medical school are commonly cited goals of medical centers and medical schools in addressing health disparities for individuals with limited English proficiency. Pre-medical education may represent a high-yield untapped opportunity to address both through a Spanish Health Topics, or Temas de Salud, course for Latino pre-health students.
\end{abstract}

Methods: The authors implemented a longitudinal course for pre-health, Latino, undergraduate students to prepare them for success in bilingual health careers. The course included educational components of health knowledge, Spanish terminology, Hispanic/Latino sociocultural context, and exposure to medical learning formats presented during monthly sessions spread out over two years. A post-course survey with comfort and knowledge assessments was administered after each one-year cycle of the program.

Results: One hundred and sixteen students (57\%) out of 203 course-participants responded to the Spanish Health Topics course survey. The student comfort level and self-perceived knowledge about specific health issues increased for both students of native-level Spanish and less advanced fluency, though a larger improvement was noted in several health topics for native speakers. Eighty-five percent of students reported perceiving the class to be useful for their future careers, and $92 \%$ of respondents indicated having applied learned concepts in social and/or academic settings outside of class.

Discussion: Most students reported benefits of the course. Future studies should focus on a more detailed evaluation of enrolled students' knowledge, attitudes, confidence, and long-term retention compared to students in a standard premedical path. Temas de Salud may enhance the bilingual, bicultural skillset of Latino underrepresented minorities in medicine, and can be replicated at other institutions.

Received 08/07/2019

Review began 08/10/2019

Review ended 09/13/2019

Published 10/02/2019

() Copyright 2019

Ortega et al. This is an open access article distributed under the terms of the Creative Commons Attribution License CC-BY 3.0., which permits unrestricted use, distribution, and reproduction in any medium, provided the original author and source are credited.
Categories: Medical Education, Public Health, Other

Keywords: hispanic/latino health, premedical education, pipeline programs, medical spanish, language concordance, premedical education, limited english proficiency, limited english proficiency, pipeline programs, underrepresented minorities, language concordance

\section{Introduction}

Medical centers struggle with the challenge of increasing underrepresented minority representation in their health workforce to better reflect their patient populations. Underrepresented minority populations have reduced access to primary care and specialty health providers. Providers who are also underrepresented minorities are more likely to serve medically underserved communities as compared to their white counterparts [1].

Linguistically and culturally concordant care is considered to be optimal for patient satisfaction and quality of care [2,3]. Hispanic/Latinos (abbreviated henceforth as "Latinos”) are significantly underrepresented in medical careers [4]. Recent national data shows that $64 \%$ of the U.S. limited English-proficient population is Spanish-speaking, whereas all other languages each comprise between 1-6\% [5]. However, there are considerably fewer Latino physicians compared to the growing number of Latino patients. A recent study showed that in the past 30 years, the number of Latino U.S. physicians per 100,000 people has declined by $22 \%[4]$.

One important factor in the decline of Latino physicians is the lack of Latino students that are pursuing higher academic levels within the sciences, including careers in Medicine. Several studies have looked at multifactorial issues associated with underrepresented minorities' declining interest over time in premedical education or research-focused careers, and worse performance on examinations compared to nonminority peers [6-9]. Some programs have had success in implementing pipeline programs that emphasize health disparities education and research development, as well as multicultural education that provides a social context of health that is distinct from biomedical science-focused education [10-12]. 
To date, no studies have formally evaluated student learning outcomes pertaining to language skills in premedical undergraduates who aim to serve a focused underserved population, such as the growing Spanish-speaking U.S. population. Regardless of their cultural background or knowledge-base, providers who treat the Latino population may have never been exposed to communication skills education to address the healthcare needs of this patient population in their preferred language. Medical Spanish programs exist at some medical institutions but mostly target practicing health professionals, medical students, or residents [13].

Some, but not all Latino pre-medical students may be considered Spanish heritage speakers-individuals who have learned Spanish as a first or second language at home, though may have significant variability in both their general Spanish language proficiency and even more so in their healthcare linguistic competency [14]. As a result, pre-medical students who are also Spanish heritage speakers may be asked to serve as ad hoc interpreters without ever having had any formal health-related or Spanish-language training. This practice has been reported to occur in a recent study involving medical students but has never been studied in prehealth undergraduates who frequently serve as volunteers, scribes, or other roles in medical centers [15]. An untrained interpretation has been shown to result in reduced quality of medical interpretation and physician-patient communication [3]. Although some researchers have evaluated the accuracy of selfreported language proficiency in medical students, and recent work has prompted a national call-to-action to increase attention to language concordance and language assessment in medical education, no data is available for healthcare Spanish training programs earlier training, such as for undergraduate pre-health students $[16,17]$.

A few programs promoting Spanish language and culture curricula and service-learning components within undergraduate pre-health programs in Hispanic-serving institutions have been described, but data has not been published regarding program outcomes such as student performance, attitudes, or comfort level $[14,18]$. Such pre-health programs serve the dual objective of increasing student medical school preparedness and of enhancing student cultural and language skills. By engaging pre-health undergraduates in a course that provides some clinical education relevant to their desired career goal, pipeline programs hope to achieve increased retention of these underrepresented students as medical professionals. The integration of language and cultural training aims to increase the eventual language concordance and communication skills of these future physicians with Spanish-speaking patients. Introducing undergraduate pre-health students to Spanish-language health care vocabulary and concepts is a potentially powerful first step in supporting the development of linguistically and culturally competent future health care providers. This novel approach to early language exposure and training may not only help to adequately prepare students for the linguistic challenges they will encounter as medical students, residents, and physicians, but it may also allow more time later in training for more advanced skill development.

The purpose of our innovative pilot program is to describe and explore the knowledge and attitudinal changes among pre-health undergraduates exposed to a clinically focused health topics curriculum in Spanish, simultaneously presenting students with health information and Spanish-language skills development.

\section{Materials And Methods}

Medicina Scholars is an existing program of the Hispanic Center of Excellence (HCOE) at the University of Illinois Chicago - College of Medicine with the goal to increase the overall retention of these students in medical careers and their ability to care for Latino patients. Thirty undergraduate Latino pre-health students per academic year are accepted into a three-year longitudinal program consisting of academic advising and a Saturday lecture series curriculum. After several years of implementation, it was recognized that this enrichment program for undergraduate students was not adequately addressing one of the key aims of the HCOE, namely, preparing the students linguistically for serving the Latino community. In response to this gap, the Temas de Salud course was designed to prepare students for success in bilingual health careers through an educational program that integrated Spanish linguistic skills.

To address the linguistic component, starting in 2015, the authors implemented a faculty-taught longitudinal Temas de Salud ("Spanish Health Topics") course to introduce pre-health track undergraduates to health-related language in Spanish. All participating students were enrolled in the Medicina Scholars program. The course was designed to increase the Spanish health knowledge base for the Medicina Scholars students and to familiarize the students with key components of future medical training. The course uses Spanish-language immersion to target basic health knowledge acquisition about specific topics, familiarize students with Spanish medical terminology, introduce the relevance of the Latino sociocultural context to health, and expose learners to medical learning formats. The four key components of the course are depicted in Figure 1. 


\section{Cureus}

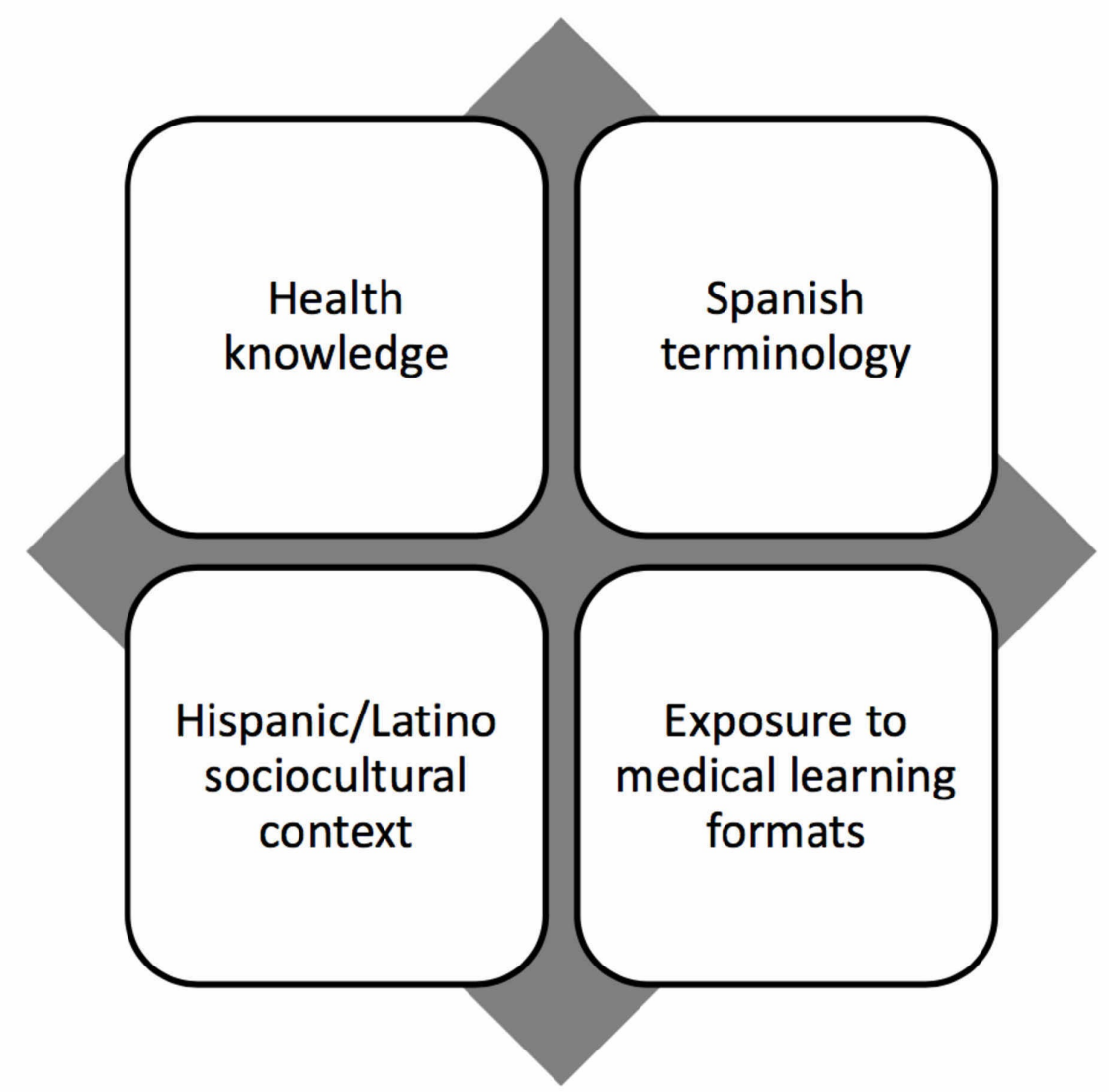

FIGURE 1: Four Components of the Temas de Salud Course

By addressing health concepts in Spanish at a level appropriate to pre-health students, the course aimed that by the end of the course, each student would: Understand basic clinically-relevant healthcare, including anatomy, physiology, common diseases, and treatments for focused, common health topics; Understand and be able to utilize Spanish-language health-related terminology; Understand the social and cultural context of the given health topic for the Latino population; Gain exposure to multiple learning formats that the students must master to succeed in a medical school, such as lectures, problem-based learning activities, multiple-choice examinations, and patient-education activities. A breakdown of the two-year longitudinal curriculum is presented in Table 1. The "Language \& Health" overview topic is taught as the first session at the beginning of each academic year to provide all new and returning students with an introduction or review of linguistic diversity, the relation of language to health care, and the role of students and physicians in delivering linguistically equitable care. All the material is taught in Spanish in an immersion-like approach, but students are encouraged to ask questions to clarify any new terminology or concepts, and combined Spanish/English explanations are provided as needed to integrate terms or ideas that students may have previously learned in English in other educational settings. All the learning activities are framed within the context of the health topics presented. 


\section{Cureus}

Breakdown of Topics By Year for 2-year Longitudinal Spanish Health Topics (Temas de Salud) Curriculum

Topic A. Language \& Health, Cultural focus: Impact of language discordance

Topic B. Cardiovascular Disease, Cultural focus: Preventive care

Year Topic C. Diabetes, Cultural focus: Myths 1 in treatment of diabetes

Topic D. Cancer, Cultural focus: Barriers to cancer screening

Topic E. Depression \& Mental Health, Cultural focus: Stigma of mental illness

Topic A. Language \& Health, Cultural focus: Impact of language discordance

Topic B. Tobacco, Alcohol \& Substance Use, Cultural focus: Strategies for community education

Topic C. Dementia, Cultural focus: Caregiver health

Topic D. Sexual \& Reproductive Health, Cultural focus: Pregnancy planning

Topic E. Hypertension \& Kidney Disease, Cultural focus: End-stage renal disease
Breakdown of Class Activities for Each Topic: Typical 2-hour class session

10 min. Large Group Activity Ice-breaker activity and quick review of prior session's teaching points.

50 min. Lecture-based new material Faculty-led presentation on the given health topic in Spanish with an emphasis on Latino patient care and cultural issues.

30 min. Small Group Activity: Problem Based Learning Students small groups to work through a case; case description, guided questions, and discussion are in Spanish.

20 min. Large Group Activity Students orally present their responses in Spanish to the cases in a large group setting followed by discussion and faculty-led summary of learning points.

$10 \mathrm{~min}$. Student feedback and quiz

TABLE 1: Curriculum Summary for Spanish Health Topics Course

After the first two years of Temas de Salud course implementation, the authors are interested in evaluating the perceived change in student comfort level with discussing health topics in Spanish, their perceived knowledge acquisition, and their performance in a post-course knowledge assessment examination.

\section{Participants}

Students were invited to participate in the study if they were undergraduate students enrolled in the Medicina Scholars program of the Hispanic Center of Excellence at the University of Illinois at Chicago College of Medicine over a two-year period from 2015-2017. Data were collected for 116 out of 203 (response rate $57 \%$ ) students. For the 2015-2016 academic year, data were collected for 56 students (55\% response rate) and for 60 students (59\% response rate) in the 2016-2017 academic year. Students were invited to participate in the survey regardless of undergraduate year, and there was no Medicina Scholar program student attrition.

\section{Data collection}

Participating students were asked to complete an electronically submitted voluntary post-course survey at the conclusion of each one-year cycle of the longitudinal Temas de Salud course. The survey asked the students to self-rate their comfort level and knowledge acquired in various categories relevant to the material presented in the course using a Likert scale, as well as to rate their opinion of course effectiveness. The survey instrument, including a proficiency self-rating scale, was based on the instrument used at the institution's medical Spanish course for medical students with adaptations appropriate to the undergraduate level and to the health topics that were being discussed [13].

Students were also asked to answer knowledge questions pertaining to the course material as an objective assessment of the material retained several months after course lectures. Knowledge questions were created by the faculty member teaching the course and feedback was provided by the Medicina Scholars' graduate assistants and faculty to ensure the questions were appropriate for students. Questions were based on the material that had been presented and/or practiced during lectures and small group activities. A select portion of the Spanish Health Topics course's assessment questions regarding self-reported proficiency and 
perceived change in knowledge/comfort questions are attached as appendices to facilitate a better understanding of the study and easier replication at other institutions.

To facilitate substantive data analysis, we asked respondents to provide their gender, nationality of Latino descent, year in college, and any prior Spanish exposure or courses they have completed. The institutional review board of the University of Illinois approved this study.

\section{Measures}

Descriptive statistics were calculated to examine overall trends in students' survey responses. We used ttests to compare means and used chi-squared tests to compare proportions and frequencies. Knowledge assessment scores are presented as the percentage of responses correct. The increase in comfort level and self-reported knowledge was also measured. The results were analyzed as differences in performance for students of varying proficiency levels. Significance was reported for $\mathrm{p}<.05$, and $\mathrm{p}<.01$. Data compilation and statistical analyses were conducted using Stata 14 (StataCorp LLC, College Station, TX).

Self-rated proficiency scales are commonly used in medical settings to guide learning activities targeting pre-course language level for medical students and physicians interested in gaining medical Spanish training [13]. The proficiency scale used in the Temas de Salud course allows respondents to choose between six proficiency categories with brief descriptions corresponding to none, beginner, low-intermediate, midintermediate, high-intermediate/advanced, and native proficiencies.

Outcome measures included: self-perceived comfort level improvement with specific health topics, perceived knowledge improvement with regards to specific course components, reported skills application outside of class, perceived utility of course-organizational elements (e.g., lecture, small group activities, large group activities), and student performance on post-course knowledge assessment questions as a measure of long-term knowledge attained. In the analysis of Likert-scale outcomes of comfort level improvement, our results will report the "strongly agree" category separately from the other responses in order to better tease out the potential differences in learning for learners with subtle distinctions in Spanish proficiency.

\section{Results}

Over two years, 116 out of 203 students (57\%) participated in the Temas de Salud course survey. Participating student undergraduate status consisted of 14\% freshmen, 20\% sophomore, 30\% junior, and $30 \%$ senior. All enrolled students self-assessed their proficiency level as intermediate level or above. About 47.4\% (55 students) classified their language skills at a native level, described as "just as comfortable conversing in Spanish as in any other language.” From the remaining students who self-assessed in intermediate categories, the majority (48 students, or $41.4 \%$ of respondents) identified as advancedintermediate, whereas only $7.6 \%$ (nine students) identified as mid-intermediate, and $3.4 \%$ (four students) as low-intermediate. Thirty-six percent of students reported growing up with a home language of Spanish only, 37\% primary Spanish-secondary English bilingual household, and 20\% primary English-secondary Spanish bilingual household. Self-reported nationality distribution among the students consisted of 85\% México, 6\% Ecuador, 3\% Puerto Rico, and 3\% Colombia. Seventy-two percent of the participants were female, and the majority of students indicated their health career goal as physician (83\%) with a few students indicating nurse practitioner (4\%) and Ph.D. researcher (3\%) as their goals. Students indicated limited prior exposure to the material presented in the course, with the majority of pre-course knowledge coming from sources such as family and peers. Only $10 \%$ of students indicated they had had any previous experience with problem based-learning prior to the Temas de Salud course.

Eighty-five percent of participants reported attending the language topic course, $41 \%$ attended the diabetes course, $38 \%$ attended the depression course, $33 \%$ attended the cancer course, $46 \%$ the tobacco and alcohol course, $45 \%$ the dementia course, $35 \%$ sexual health, and $34 \%$ hypertension, with an average attendance rate of $42 \%$ for each session.

Table 2 shows the score reports from a summative knowledge assessment examination that students completed at the end of the course. The displayed results are separated by content-area covered in the Temas de Salud course to identify student performance in different topic areas. Scores represent the percentage of questions that were answered correctly by each student, and the results are shown for students at native versus intermediate proficiency levels; the intermediate proficiency includes the low, mid, and advancedintermediate subcategories described above. 


\section{Cureus}

\begin{tabular}{|c|c|c|c|c|c|c|c|c|c|c|}
\hline \multirow{2}{*}{ Area Assessed } & \multicolumn{3}{|c|}{ Intermediate Proficiency } & \multicolumn{3}{|c|}{ Native Proficiency } & \multicolumn{3}{|c|}{ Overall } & \multirow{2}{*}{ p-value } \\
\hline & $\mathrm{n}$ & Mean & SD & $\mathrm{n}$ & Mean & SD & $\mathrm{n}$ & Mean & SD & \\
\hline Language \& Health overview & 52 & 54 & 3 & 50 & 68 & 3 & 102 & 61 & 3 & .002 \\
\hline Diabetes & 27 & 47 & 5 & 23 & 46 & 6 & 50 & 47 & 4 & .527 \\
\hline Cardiovascular & 27 & 59 & 4 & 23 & 61 & 4 & 50 & 60 & 3 & 391 \\
\hline Depression & 27 & 89 & 4 & 23 & 83 & 5 & 50 & 86 & 3 & .847 \\
\hline Cancer & 27 & 63 & 6 & 23 & 71 & 6 & 50 & 67 & 4 & .169 \\
\hline Tobacco \& alcohol & 25 & 87 & 4 & 27 & 88 & 6 & 52 & 87 & 4 & .450 \\
\hline Dementia & 25 & 60 & 6 & 27 & 64 & 5 & 52 & 62 & 4 & .297 \\
\hline Sexual health & 25 & 83 & 4 & 27 & 85 & 4 & 52 & 84 & 3 & .330 \\
\hline Hypertension and kidney & 25 & 56 & 5 & 27 & 56 & 6 & 52 & 56 & 4 & .522 \\
\hline Total & 53 & 67 & 2 & 50 & 71 & 2 & 103 & 69 & 1 & .074 \\
\hline
\end{tabular}

\section{TABLE 2: Knowledge Assessment Score Distribution by Content Area}

Note: p-values based on t-test

Note: Scores represent percentage correct responses on knowledge assessment examination.

Table 3 depicts the self-reported increase in student comfort level and knowledge about specific health issues discussed in the course as varied by student's baseline Spanish proficiency level. The table displays the percentage of students who strongly agreed that the course improved their comfort level in discussing the indicated health topics. On average, only a small percentage (3.1\%) of students disagreed or strongly disagreed with this statement for any of the health topics. To better tease out the differences in learning for learners with more subtle distinctions in Spanish proficiency, we, therefore, have displayed the "strongly agree" category separately from those who selected "agree." While most students reported agreeing or strongly agreeing, on a Likert scale, that the course improved their comfort and knowledge about each health topic, areas such as diabetes, mental health, and dementia demonstrated a larger improvement for students with native-level proficiency compared to those with lower self-reported proficiency levels. Less advanced students reported increased utility, on a Likert scale, of the presentation handouts for their knowledge improvement $(82 \%$ non-native speakers versus $51 \%$ native speakers, $\mathrm{P}<.001$ ). 


\section{Cureus}

\begin{tabular}{|c|c|c|c|c|c|}
\hline Content & Item & $\begin{array}{l}\text { Intermediate } \\
\text { Proficiency }\end{array}$ & $\begin{array}{l}\text { Native } \\
\text { Proficiency }\end{array}$ & Total & $\begin{array}{l}\text { p- } \\
\text { value }\end{array}$ \\
\hline \multirow{17}{*}{$\begin{array}{l}\text { Temas de Salud increased my comfort level in } \\
\text { the following Health Topics in Spanish }\end{array}$} & When medical interpreter is needed & 62.07 & 71.70 & 66.67 & .282 \\
\hline & What is diabetes? ${ }^{\star}$ & 41.38 & 69.57 & 53.85 & .043 \\
\hline & How to improve risk of diabetes ${ }^{\star \star}$ & 37.93 & 78.26 & 55.77 & .004 \\
\hline & Complications of diabetes $^{\star \star}$ & 31.03 & 69.57 & 48.08 & .006 \\
\hline & What is cardiovascular disease? & 40.74 & 52.38 & 45.83 & 422 \\
\hline & What is cholesterol? & 33.33 & 59.09 & 44.90 & .071 \\
\hline & What is mental health?* & 44.44 & 73.68 & 56.52 & .049 \\
\hline & Causes of mental disorders & 48.15 & 55.56 & 51.11 & .626 \\
\hline & What is depression? & 44.44 & 68.42 & 54.35 & 108 \\
\hline & What is cancer? & 54.17 & 50.00 & 52.50 & .796 \\
\hline & What does cancer stage mean? & 54.17 & 50.00 & 52.50 & .796 \\
\hline & Recommended cancer screening & 50.00 & 56.25 & 52.50 & .698 \\
\hline & Consequences of tobacco use ${ }^{*}$ & 53.85 & 80.00 & 67.86 & .037 \\
\hline & Consequences of alcohol use & 59.26 & 80.00 & 70.18 & .087 \\
\hline & What is dementia?* & 47.83 & 79.31 & 65.38 & .018 \\
\hline & What to do if you suspect dementia & 60.87 & 65.52 & 63.46 & .730 \\
\hline & Cultural norms for sexual health & 61.54 & 80.77 & 71.15 & .126 \\
\hline \multirow{11}{*}{ Temas de Salud increased my knowledge } & Medical sexual health terminology & 54.17 & 64.00 & 59.18 & .484 \\
\hline & $\begin{array}{l}\text { Prevalence of sexually transmitted } \\
\text { infections/teen pregnancy }\end{array}$ & 65.38 & 57.69 & 61.54 & .569 \\
\hline & What is blood pressure? & 58.33 & 62.07 & 60.38 & .782 \\
\hline & Consequences of hypertension & 60.00 & 62.07 & 61.11 & .876 \\
\hline & What is kidney disease? & 54.55 & 60.00 & 57.45 & .706 \\
\hline & Overall health terminology & 63.79 & 64.81 & 64.29 & .910 \\
\hline & General health knowledge & 74.14 & 72.22 & 73.21 & .819 \\
\hline & Cultural knowledge & 72.41 & 79.63 & 75.89 & .372 \\
\hline & Patient communication skills & 68.97 & 66.67 & 67.86 & .795 \\
\hline & Info about common diseases & 67.24 & 68.52 & 67.86 & .885 \\
\hline & Healthy lifestyle/prevention choices & 70.18 & 72.22 & 71.17 & .812 \\
\hline
\end{tabular}

TABLE 3: Increase in Comfort Level and Self-reported Knowledge by Language Proficiency: Proportion (\%) of Strongly Agree

Note: ${ }^{*} p<.05,{ }^{* \star} p<.01 ; p$-values based on $\mathrm{x} 2$ test

Eighty-five percent of all respondents indicated strong agreement with the statement that the class adequately introduced them to key health topics in Spanish that will be useful in their intended career. Moreover, a vast majority (92\%) of respondents indicated that they had had an opportunity to apply the skills taught in the Spanish Health Topics course in various social and academic settings; $72 \%$ reported using the learned skills with their family, $45 \%$ indicated applying the skills with friends, $30 \%$ used them in clinical settings (such as volunteering or shadowing experiences), $23 \%$ used the skills at school, and 16\% at work. 


\section{Discussion}

Initial data suggests that there are some differences in the outcomes among Spanish heritage speakers based on their starting proficiency level. For example, native speakers have a greater capacity to increase their knowledge base based on oral lectures, whereas less advanced speakers report greater benefit from handouts and written materials that may help them to review or reinforce the material outside of class time. Most of their knowledge assessment scores did not differ significantly based on proficiency level.

A few topic areas, however, did display some knowledge differences with more fluent speakers performing better on the assessment, such as mental health, dementia, and diabetes. The reasons for detecting a difference in performance among students who self-reported native versus non-native proficiency may include variations in self-reporting practices (e.g., some students may overestimate or underestimate their proficiency) or difference in the perceived complexity of the topic presented. For example, students at a more advanced proficiency level may have had more prior exposures to certain health topics than less fluent students who may not be as likely to have discussed those concepts in Spanish in the past. Of note, the first topic ("language and health overview") displays twice the number of student survey responses since this topic is taught as the first session at the beginning of each academic year. Therefore, response data to knowledge questions about this topic are asked at the conclusion of the course after every academic year, whereas the focused health topic areas of the other sessions are different in year-one versus year-two of the curriculum (Table 1 ).

For future studies, the post-course data should be compared with an objective pre-course knowledge assessment and results should be compared to a control group of pre-health students who receive standard pre-medical courses without the supplemental Spanish health topics curriculum. In addition, the study's self-reported proficiency and comfort level assessments may be limited in accuracy, and expanded pre- and post-assessment of students should be considered in future investigations to better understand both preexisting knowledge base about specific topics, language proficiency, and effect of the educational intervention.

For most students, Temas de Salud represents an intervention that provides the first opportunity for formal learning of health and clinical information that has applicability and impact not only to their future career but also to their current lives, as evidenced by their usage of the information with their families, friends, and in other life contexts. Many students provided free-text feedback as part of their survey responses, and several commented that they valued gaining knowledge regarding Spanish medical terminology that they anticipate to be a necessity for them in their medical training. One student summarized that the course "introduced me to Spanish words I did not know but will need to know for my future career."

Others commented on the importance of the cultural connection to their heritage language, such as the student who commented: "I had never before taken a course or listened to an academic lecture in my native language, so this exposure was definitely beneficial." Another student mentioned "having discussions in Spanish, I really enjoyed that. I would probably never had the experience anywhere except here." Many students made connections between content presented in the course and the ability to care for their family members and community. This is consistent with prior literature that underrepresented minority physicians are more likely to care for underserved populations, although the effect of physician's multilingual skills on practice location decisions has not been studied [19]. One Temas de Salud student wrote, "It definitely helped me to be able to communicate this to my own family and be more open-minded. I am actually looking forward to educating myself [further] on these topics in Spanish" indicating motivation to continue gaining language and cultural skills. Yet another student stated, “[In] college we don't really talk about health problems in [the] Latino community, [but throughTemas de Salud] every month, I am reminded why I am here, why I am studying, and why medicine was my passion, [to] help my underrepresented community.”

Anecdotal reports from Temas de Salud students suggest that after their experience in the course, participants are choosing to enrich their undergraduate careers such as adding double-majors, minors, or other coursework with the goal of improving their linguistic competence in Spanish. To our knowledge, Medicina Scholars is the first pre-professional pipeline program with a formal Spanish curriculum that is tracking student performance and comfort level in an effort to provide the evidence base to support the development of health-related language and cultural skill set in pre-medical underrepresented students. Additional studies tracking students over time may help establish the long-term benefits of a Spanish Health Topics course for pre-medical undergraduates on target criteria such as matriculation in medical school, academic performance metrics, the likelihood of future practice in underserved communities, and student career satisfaction.

\section{Conclusions}

The integration of health concepts through a Spanish-immersion program for Latino pre-health students can improve student comfort level, enhance knowledge acquisition, and promote culturally-relevant health concept applications to students' social and academic environments. Temas de Salud is a pilot program that may serve as a model for pre-health training to increase the Spanish health language and culturally-relevant exposure and preparedness of Latino premedical undergraduates. Our course builds upon Latino students' 


\section{Cureus}

heritage language skills and cultural experiences and enhances their skills as applied to medical contexts. Such strategies that build upon Latino or other underrepresented minorities' pre-existing knowledge base may serve to validate their diverse lived experience as a valuable clinical asset that can be supported by formal educational efforts. Temas de Salud aims to empower Latino students to value and enhance their bilingual, bicultural health skillset early in their career path. As such, our program represents an opportunity for replication in other undergraduate institutions that may be interested in developing pipeline programs to promote underrepresented, multilingual minorities in medicine.

\section{Appendices}

\section{Temas de Salud Post-course Survey - Ortega}

Prior Spanish Level

Please answer the following questions about your Spanish level and previous exposure.

* 2. What is your current level of general Spanish fluency?

0- None

1 - Knows/understands scattered words

2 -Able to use some simple words and phrases, but still has limited receptive understanding

3 - Able to have a simple dialogue (e.g., food, the weather) using full sentences

4 - Able to converse with more sophisticated conjugation skills (past, present, future tenses) \& more robust vocabulary

5 - Native level fluency. As comfortable conversing in Spanish as in any other language.

* 3. What prior formal Spanish education have you had (not including Temas de Salud)? (Check all that apply.)

$\square$ None

Spanish coursework in high school

Spanish coursework in college

Health-related Spanish course (please describe in comment box)

Other (please describe in comment box)

Other (please specify)

* 4. What language(s) was(were) spoken at home when you were growing up?

Spanish ONLY

English ONLY

Spanish as primary language; English as secondary language

English as primary language; Spanish as secondary language

Other (please specify)

FIGURE 2: Selected Proficiency Questions from the Temas de Salud Assessment Instrument 


\section{Cureus}

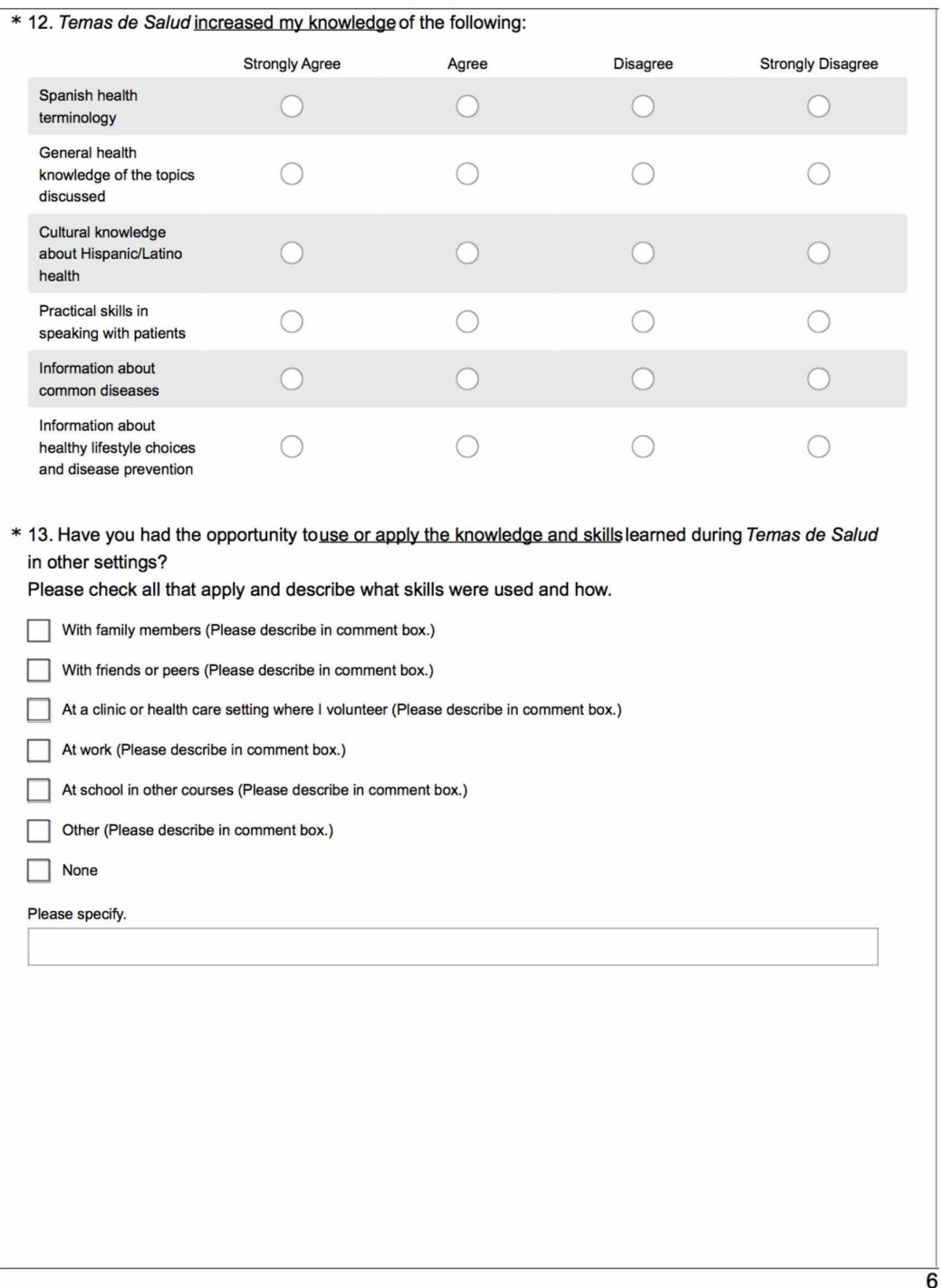

FIGURE 3: Selected Perceived Change in Knowledge Questions from the Temas de Salud Assessment Instrument

\section{Additional Information}

\section{Disclosures}

Human subjects: Consent was obtained by all participants in this study. University of Illinois at Chicago issued approval Protocol \# 2016-0309 Approved as IRB Exempt. The OPRS staff/members of Institutional Review Board (IRB) \#7 have reviewed and approved this amendment to your research, and have determined that your amended research continues to meet the criteria for exemption as defined in the U. S. Department of Health and Human Services Regulations for the Protection of Human Subjects [(45 CFR 46.101(b)]. Animal subjects: All authors have confirmed that this study did not involve animal subjects or tissue. Conflicts of interest: In compliance with the ICMJE uniform disclosure form, all authors declare the following: Payment/services info: All authors have declared that no financial support was received from any organization for the submitted work. Financial relationships: Pilar Ortega, MD declare(s) royalties from Saunders Elsevier. Pilar Ortega, MD receives author royalties from Saunders Elsevier. Other relationships: All authors have declared that there are no other relationships or activities that could appear to have influenced the submitted work.

\section{References}

1. Smith SG, Nsiah-Kumi PA, Jones PR, Pamies RJ: Pipeline programs in the health professions, part 1: 
preserving diversity and reducing health disparities. J Natl Med Assoc. 2009, 101:836-851. 10.1016/s00279684(15)31030-0

2. Fernández A, Schillinger D, Grumbach K, Rosenthal A, Stewart AL, Wang F, Pérez-Stable EJ: Physician language ability and cultural competence. An exploratory study of communication with Spanish-speaking patients. J Gen Intern Med. 2004, 19:167-74. 10.1111/j.1525-1497.2004.30266.X

3. Divi C, Koss RG, Schmaltz SP, Loeb JM: Language proficiency and adverse events in US hospitals: a pilot study. Int J Qual Health Care. 2007, 19:60-7. 10.1093/intqhc/mzl069

4. Sánchez G, Nevárez T, Schink W, Hayes-Bautista DE: Latino physicians in the United States, 1980-2010: a thirty-year overview from the censuses. Acad Med. 2015, 90:906-912. 10.1097/ACM.0000000000000619

5. Zong J, Batalova J: The limited English proficient population in the United States . Migration Policy Institute. 2015, Accessed: July 28, 2019: http://www.migrationpolicy.org/article/limited-english-proficientpopulation-united-states.

6. Barr, DA, González ME, Wanat SF: The leaky pipeline: Factors associated with early decline in interest in premedical studies among underrepresented minority undergraduate students. Acad Med. 2008, 83:503-511. 10.1097/ACM.0b013e31816bda16

7. Hadinger MA: Underrepresented minorities in medical school admissions: a qualitative study . Teach Learn Med. 2017, 29:31-41. 10.1080/10401334.2016.1220861

8. Krupat E, Camargo CA, Strewler GJ, Espinola JA, Fleenor TJ, Dienstag JL: Factors associated with physicians' choice of a career in research: a retrospective report 15 years after medical school graduation. Adv Health Sci Educ Theory Pract. 2017, 22:5-15. 10.1007/s10459-016-9678-5

9. Segers-Jager KM, Brommet FN, Themmen APN: Ethnic and social disparities in different types of examinations in undergraduate pre-clinical training. Adv Health Sci Educ Theory Pract. 2016, 21:1023-1046. 10.1007/s10459-016-9676-7

10. Salto LM, Riggs ML, Delgado De Leon D, Casiano CA, De Leon M: Underrepresented minority high school and college students report STEM-pipeline sustaining gains after participating in the Loma Linda University summer health disparities research program. PloS One. 2014, 9:9. 10.1371/journal.pone.0108497

11. Metz AM: Medical school outcomes, primary care specialty choice, and practice in medically underserved areas by physician alumni of MEDPREP, a postbaccalaureate premedical program for underrepresented and disadvantaged students. Teach Learn Med. 2017, 29:351-359. 10.1080/10401334.2016.1275970

12. Kumagai, AK, Lypson, ML: Beyond cultural competence: critical consciousness, social justice, and multicultural education. Acad Med. 2009, 84:782-787. 10.1097/ACM.0b013e3181a42398

13. Ortega P, Park YS, Girotti JA: Evaluation of a medical Spanish elective for senior medical students: improving outcomes through OSCE assessments. Med Sci Educ. 2017, 27:329-337. 10.1007/s40670-0170405-5

14. Martínez GA: Medical Spanish for heritage learners: a prescription to improve the health of Spanishspeaking communities. Building Communities and Making Connections. Cambridge Scholars Publishing in association with GSE, 2010. 14:2-15. 10.5848/CSP.2022.00001

15. Vela MB, Fritz C, Girotti, J: Medical students' experiences and perspectives on interpreting for LEP patients at two US medical schools. J Racial Ethn Health Disparities. 2016, 3:245-249. 10.1007/s40615-015-0134-7

16. Reuland DS, Frasier PY, Olson MD, Slatt LM, Aleman MA, Fernandez A: Accuracy of self-assessed Spanish fluency in medical students. Teach Learn Med. 2009, 21:305-9. 10.1080/10401330903228489

17. Ortega P: Spanish language concordance in U.S. medical care: a multifaceted challenge and call to action . Acad Med. 2018, 93:1276-1280. 10.1097/ACM.0000000000002307

18. Ghaddar S, Ronnau J, Saladin SP, Martínez G: Innovative approaches to promote a culturally competent, diverse health care workforce in an institution serving Hispanic students. Acad Med. 2013, 88:1870-6. 10.1097/ACM.0000000000000007

19. Rodríguez JE, Campbell KM, Pololi LH: Addressing disparities in academic medicine: What of the minority tax?. BMC Med Educ. 2015, 15:6. 10.1186/s12909-015-0290-9 